\title{
CORRECTION
}

\section{Correction to: p63 regulates the caspase-8-FLIP apoptotic pathway in epidermis}

S. Borrelli, E. Candi, D. Alotto, C. Castagnoli, G. Melino, M. A. Viganò and R. Mantovani

( ) The Author(s), under exclusive licence to ADMC Associazione Differenziamento e Morte Cellulare 2021

Cell Death \& Differentiation (2023) 30:221-223; https://doi.org/10.1038/s41418-021-00896-8

Correction to: Cell Death and Differentiation (2009) 16: 253-263; https://doi.org/10.1038/cdd.2008.147; Article published online 17 October 2008

The authors wish to correct the following errors. In Figure 1B, there is a duplication of Caspase 8 RT-PCR Panels. We now show the correct 27 and 28 cycles Panels. In Figure $3 \mathrm{~A}$ (sh Ctl), the $250 \mathrm{~J} / \mathrm{m}^{2}$ DAPI Panel was erroneously duplicated into the $400 \mathrm{~J} / \mathrm{m}^{2}$ section. We now show the correct DAPI file of the $400 \mathrm{~J} / \mathrm{m}^{2}$ section. These errors neither affect the results nor the conclusion of the article. The authors apologize to the readers for any inconvenience which might have been caused. 
Fig. 1

a

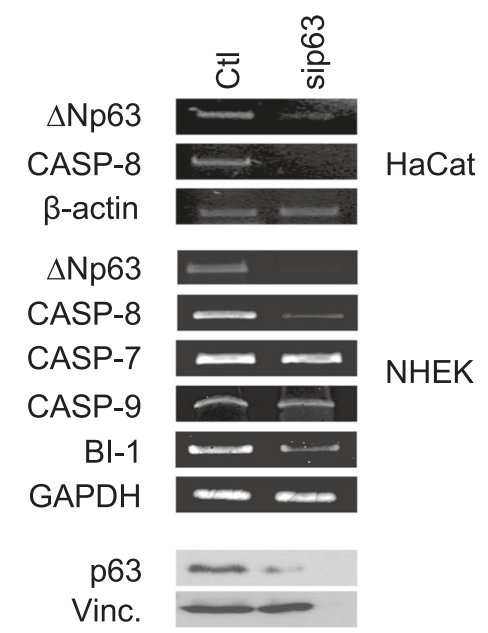

b

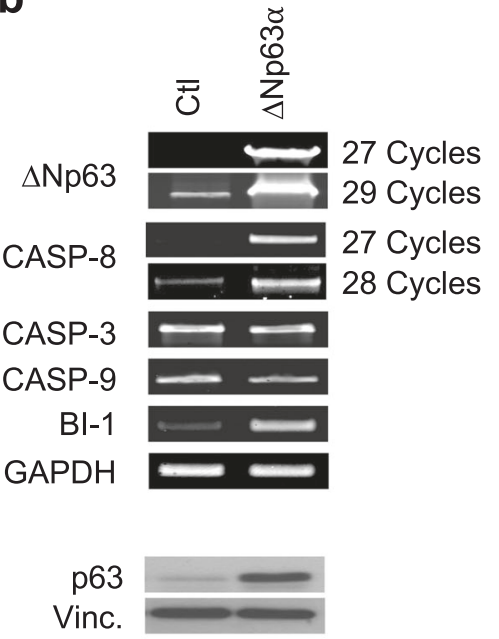

C
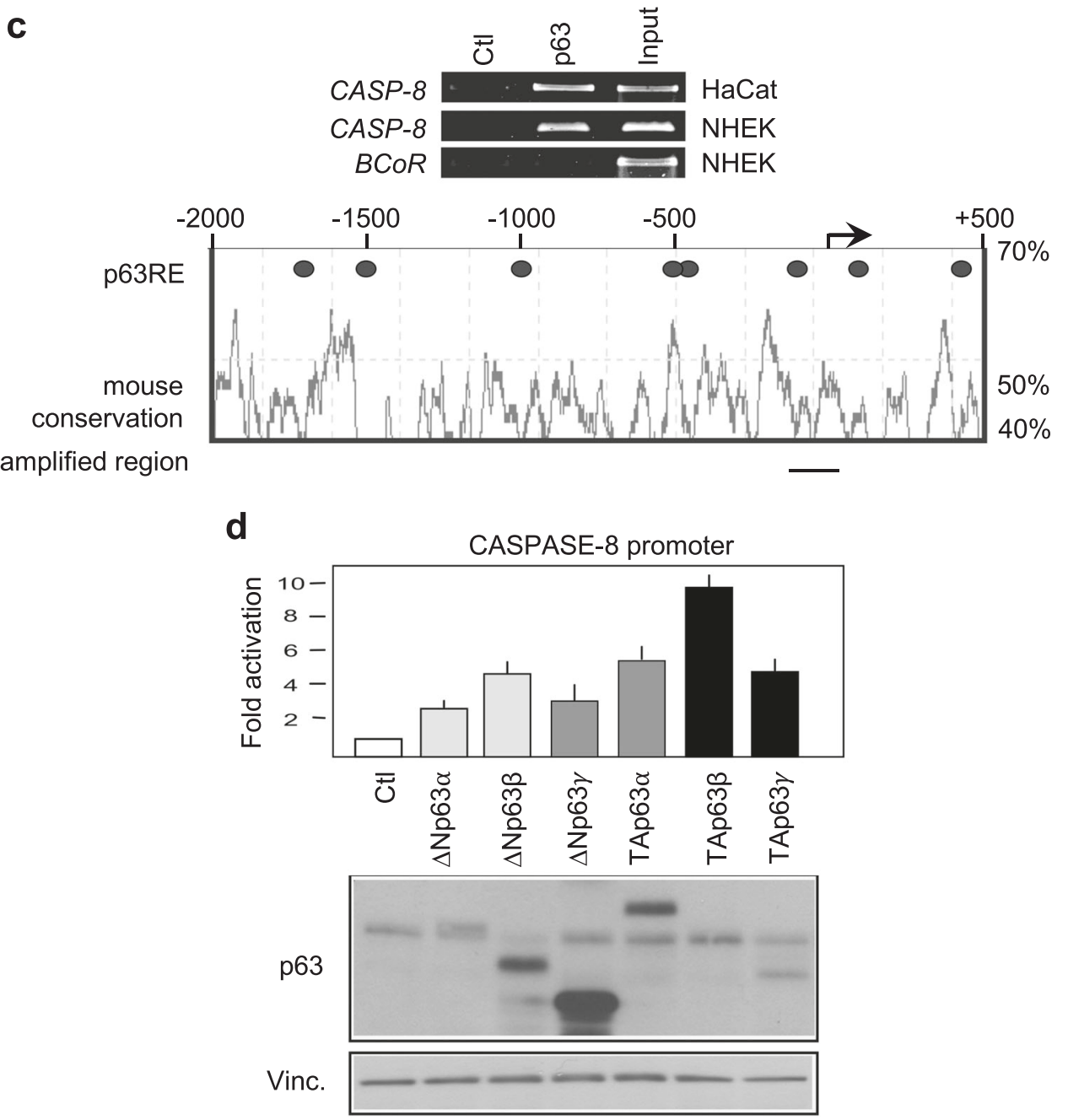
Fig. 3

a

\section{Cleaved}
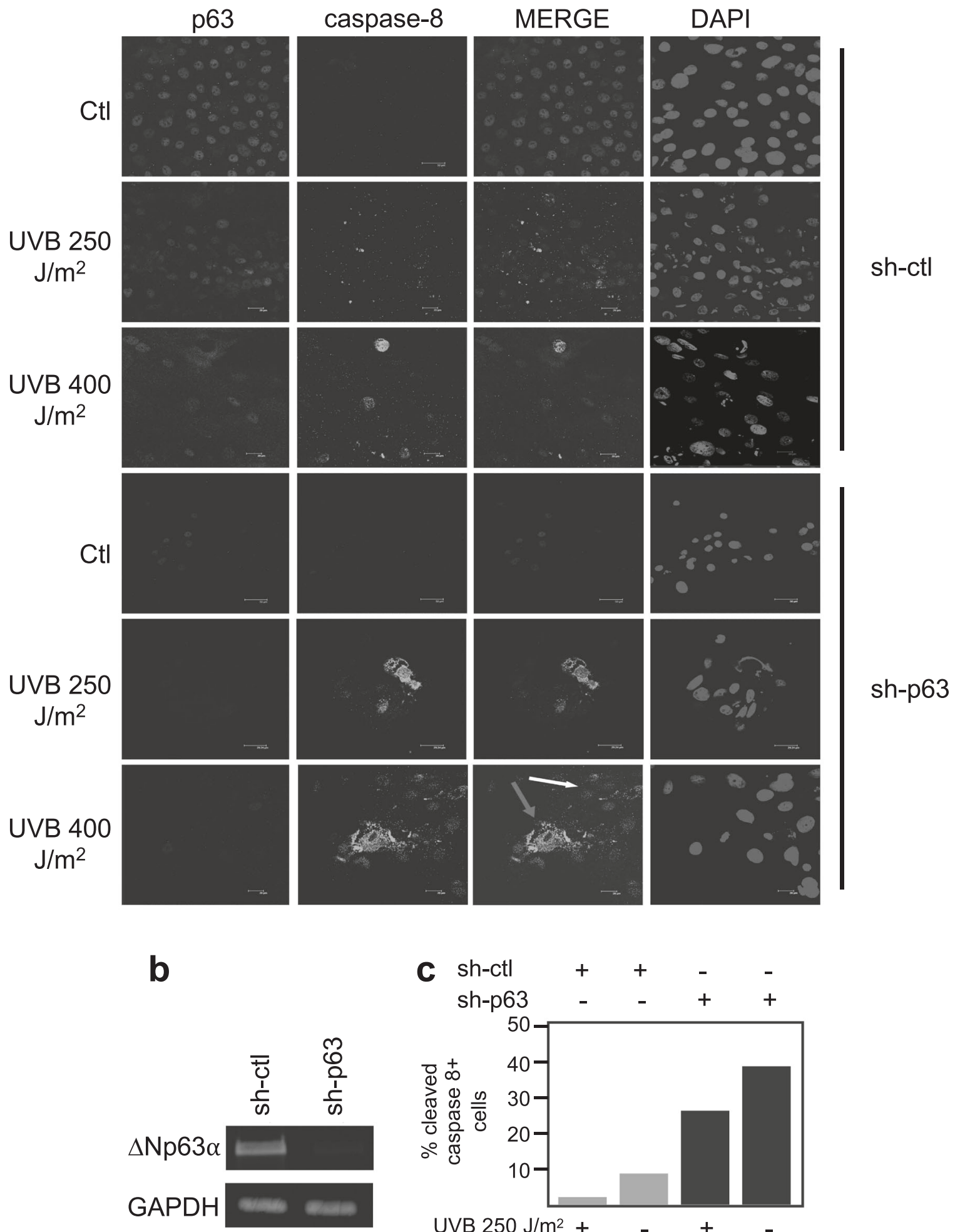

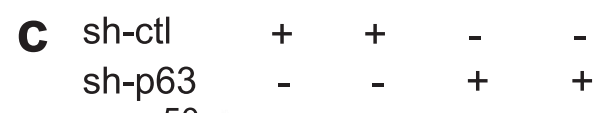

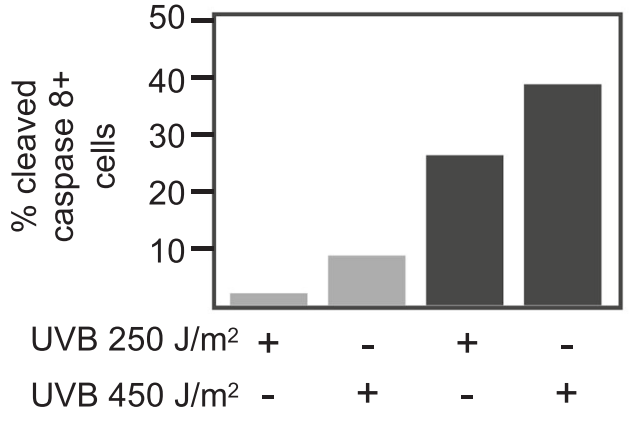

